\title{
Response to COVID-19 pandemic in the UAE: A public health perspective
}

\section{Farida Al Hosany ${ }^{1}$, Subhashini Ganesan ${ }^{2}$, Shammah Al Memari ${ }^{1}$, Shereena Al Mazrouei ${ }^{1}$, Faheem Ahamed ${ }^{2}$, Ashish Koshy ${ }^{2}$, Walid Zaher ${ }^{2}$}

\section{Sustained communication and con- stant engagement with the public had been the corner stone of the successful battle against COVID-19 by the UAE government.}

\begin{abstract}
]
\end{abstract} $\mathrm{n}$ the current pandemic of COVID-19 affecting countries across the globe, there are wide variations on how each country is handling the crisis. World leadership, economic status of the country, health care incomes imperative to understand how the current pandemic, the biggest public health crisis, was handled in the UAE from a public health perspective.

\section{THE UAE IN COMBATING COVID-19}

The World Health Organization (WHO) has released recommendations on strategic preparedness and handling of the COVID-19 pandemic [1]. Based on this, the article aims at discussing the UAE's efficient combat of COVID-19 crisis under six priority areas of work.

\section{Emergency response mechanism}

The emergency response system of the UAE is managed by National Crisis and Emergency Management Authority (NCEMA) and the UAE government was vigilant in issuing the first alert of the new coronavirus outbreak, even before it was declared by WHO as a public health emergency of international concern [2].

The UAE has a comprehensive, government-funded health service as well as private health facilities which delivers a high standard of health care to the population.

During this pandemic, the entire health care system was prepared and alerted with protocols in place for efficient handling of the crisis

Table 1 gives details of various circulars released by the government ( $\mathrm{DOH}$, ADPHC) related to the preparedness and management of the COVID-19 pandemic [3]. 
Table 1. Circulars and protocols released by the UAE government in handling COVID-19 [3]

\begin{tabular}{|c|c|c|}
\hline DATE & TITLE & REFERENCE \\
\hline $21 / 1 / 2020$ & Novel Coronavirus alert & ADPHC-DG/C/01/2020 \\
\hline $6 / 2 / 2020$ & Coverage of novel corona screening & USO/04/2020 \\
\hline $2 / 3 / 2020$ & Novel Coronavirus circular (COVID-19) & ADPHC-DG/C/05/2020 \\
\hline $3 / 3 / 2020$ & Novel Coronavirus circular (COVID-19) & ADPHC-DG/C/06/2020 \\
\hline $8 / 3 / 2020$ & Coverage of corona virus disease 2019 (COVID-19) screening and treatment & USO/07/2020 \\
\hline $22 / 3 / 2020$ & Diagnostic test for Corona (COVID-19) & USO/09/2020 \\
\hline $24 / 3 / 2020$ & Diagnostic test for Corona (COVID-19) & USO/11/2020 \\
\hline $24 / 3 / 2020$ & Licensed Healthcare Professional Rotation between Abu Dhabi Licensed Healthcare Facilities & USO/12/2020 \\
\hline $26 / 3 / 2020$ & Effective hand sanitising products for COVID-19 pandemic & HLME/08/2020 \\
\hline $26 / 3 / 2020$ & Safe working practices for OP pharmacies due to Covid-19 pandemic & HLME/07/2020 \\
\hline $30 / 3 / 2020$ & Novel Coronavirus circular (COVID-19) & USO/16/2020 \\
\hline $6 / 4 / 2020$ & Epidemiological Surveillance \& Reporting of COVID-19 Cases & USO/18/2020 \\
\hline $09 / 4 / 2020$ & Implementing medical home visits for corona virus (COVID-19) high risk categories & USO-22-2020 \\
\hline $90 / 4 / 2020$ & Novel Coronavirus circular (COVID-19 & USO-21-2020 \\
\hline $06 / 5 / 2020$ & Coverage of corona virus disease 2019 (COVID-19) diagnostic and treatment services & USO-38-2020 \\
\hline $24 / 5 / 2020$ & Covering corona virus (COVID-19) test in the activity based funded mandates (ABMs) & USO-51-2020 \\
\hline $28 / 5 / 2020$ & Rational use of Personal Protective Equipment (PPE) as per Clinical Setting in Context of COVID-19 Response & USO/54/2020 \\
\hline $28 / 5 / 2020$ & Testing of COVID-19 for Healthcare Workers & USO/52/2020 \\
\hline $2 / 7 / 2020$ & Interim rules and requirements to minimize chance for exposures and to prevent spreading COVID-19 between HCWs. & USO/55/2020 \\
\hline $7 / 72020$ & Updated National Protocol for Clinical Management and Treatment of COVID-19. & USO/57/2020 \\
\hline $5 / 7 / 2020$ & Guidelines for COVID-19 Serology & USO/61/2020 \\
\hline $12 / 7 / 2020$ & Coverage of Coronavirus disease 2019 (COVID-19) Diagnostic and treatment services & USO/68/2020 \\
\hline $16 / 8 / 2020$ & Comprehensive COVID-19 Guideline for Healthcare Professionals in Abu Dhabi. & USO/80/2020 \\
\hline $5 / 10 / 2020$ & COVID-19 screening test for all health care workers (HCWs) & USO/109/2020 \\
\hline
\end{tabular}

HCW - health care worker

\section{Risk communication and public engagement}

Risk communication is a key factor during a pandemic and the UAE government executed a detailed awareness campaign that targeted different groups of the community and provided a daily update about the status of the disease locally and internationally. UAE adopted the mandatory use of face masks in March 2020 well ahead of the WHO recommending this policy [4]. Smart technology platform was effectively used in the UAE to combat COVID-19, for example, a chatbot service was established by MoHAP called "Virtual doctor for COVID-19. The "Doctor for every citizen" app was also made available for people for providing COVID-19 related information and services. The "Weqaya" platform, by NCEMA, was utilized to enhance awareness among the public on the ongoing COVID-19 public health crisis."

The role of G42 Healthcare is an exemplar of the strategic relevance and importance of public-private-academic partnerships, whereby expertise from the private sector are integral to the crisis management and risk mitigation programs
The ALHOSN UAE app is the official integrated digital platform for COVID-19 tests in the UAE through which individuals can receive COVID-19 test results on their smartphones. Similarly, the StayHome app supported quarantine and isolation of patients [5].

The coronavirus helpline was established by the Ministry of Health and Prevention (MoHAP), as well as a hotline for mental health counselling to respond to psychological concerns and anxiety of people during the pandemic [5].

\section{Case finding, contact tracing and management}

The government of the UAE made remarkable progress in testing for the SARS-CoV-2 virus and in the management of cases. Algorithms for segregation, isolation, and treatment were released to guide health care professionals in handling COVID-19 cases (Table 1).

In the UAE, testing services were promptly provided in most health care facilities across the nation and for the ease of testing, drive through testing centres were established by the Department of Health - Abu Dhabi and SEHA. These centres were equipped with the most advanced testing systems, techniques, and globally accredited health care teams [6]. 
By the directives of His Highness Sheik Mohamed Bin Zayed Al Nahyan, Crown Prince of Abu Dhabi and Deputy Supreme Commander of the Armed Forces, free tests were provided to Emiratis, domestic workers in Emirati households, people of determination, pregnant women, residents aged over 50 years, people with chronic diseases, those with coronavirus symptoms and all contacts of the coronavirus patients.

Mass testing campaigns were conducted in crowded pockets where there was high risk of transmission [7], these intense measures were very effective in breaking the chain of transmission.

Field hospitals were set up in the UAE to ease the pressure on city-based hospitals and to aid faster response to COVID-19. The first field hospital in the UAE was opened at the Dubai World Trade Centre with a capacity of 300 beds, that can be expanded up to 3000 beds.

The Abu Dhabi Health Services Co (SEHA) has set up similar field hospitals at various locations and apart from these, a quarantine facility called Complex 3, with a capacity to quarantine 10000 patients was set up. The government vigorously worked to establish this in only 9 days [8].

All these facilities followed rigid COVID -19 protocols in handling and management of cases.

\section{Surveillance of COVID-19}

Circulars were released for all health care professionals and a series of training workshops were conducted to educate health care professionals about the disease diagnosis, reporting, and management to strengthen epidemiological surveillance and enhancing prompt reporting of all suspected COVID-19 cases to Abu Dhabi Public Health Centre (ADPHC). In addition, active surveillance was established to identify Severe Acute Respiratory Infections (SARI) admitted to different hospitals there are required to be tested for COVID-19 (Table 1).

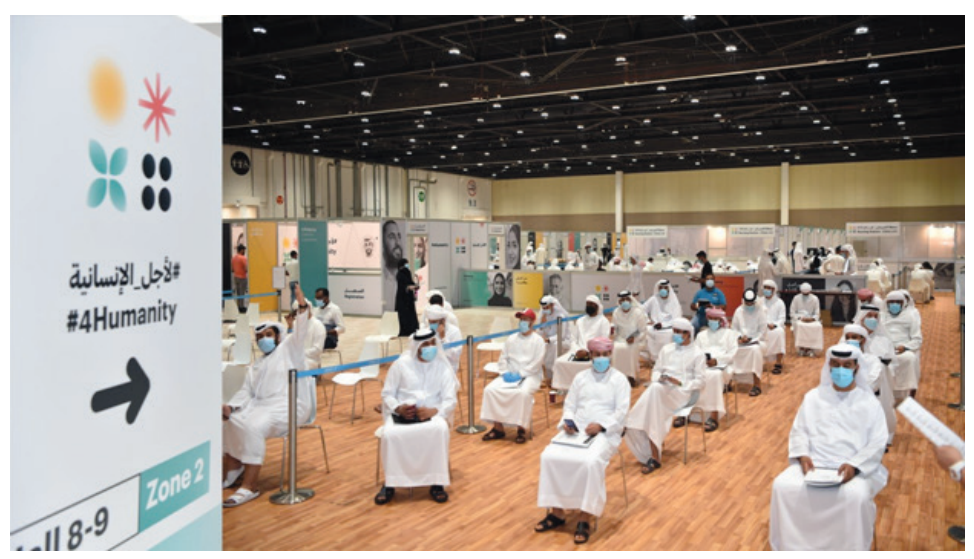

Photo: \#4 Humanity Phase III Clinical trial, a key initiative to foster population health and to enhance UAE's medical and research capabilities (Credit: \#4Humanity Media Office, G42 Healthcare).

\section{Vigorous public health measures to contain and combat COVID-19}

The UAE is adopting the most demanding standard of two metres, double the distance recommended by the World Health Organisation. This had played a significant role in curbing the infections.

The UAE was one of the first countries to efficiently adapt remote learning in all private and government schools. The federal and local governments in the UAE adopted a remote working system to ensure the health and safety of its employees and customers. The government also issued orders to temporarily stop the distribution of all print newspapers, magazines, and marketing material to avoid transmission of virus by contact [9].

The UAE Government suspended all close gatherings and sports activities, commercial centers, shopping malls along with fish, meat, and vegetables markets were closed except for essential commodities. To contain the virus and to restrict entry of people into the UAE, which is an essential precautionary measure to curb the spread, the UAE suspended visas to all foreigners and all inbound and outbound passenger flights were cancelled [9]. The government announced enforcement of penalties to violators who threaten public health.

The country launched the world's first phase III clinical trials (\#4 Humanity clinical trial) for COVID-19 inactivated vaccine in July 2020 by G42 Healthcare in collaboration with Sinopharm CNBG, Department of Health, Abu Dhabi and UAE Ministry of Health and Prevention. This is a vivid example of national initiatives to foster population health and to enhance the UAE's medical research and development capabilities [10]. The vaccine is authorized for use and is given free of cost for all residents of the UAE. The UAE leads in top rankings for highest rate of vaccination [11].

SEHA plays a vital role in getting the residents vaccinated and it has vaccination centers established in various other Emirates for effective functioning and reach.

\section{Societal response}

The final priority work area for preparedness in dealing with this pandemic would be to develop all-of-society and business continuity plans. The UAE government is already leading the way in restarting business and 
announced a two-phase recovery plan to rebuild the economy [12]. The two biggest economies in the UAE, Dubai and Abu Dhabi have taken a holistic approach to economic revival. They have made decisions to relieve troubled businesses facing administrative penalties along with the stimulus package of US\$79 billion for private sector in the first phase and in the next phase there is a long-term stimulus plan to speed up the recovery and encourage investments in digital economy like $5 \mathrm{G}$ networks and Artificial Intelligence, these are examples of how governments can implement a holistic approach to reboot economic growth. The UAE government along with the supreme Council of National security and NCEMA have released guidelines for Business continuity for UAE organizations.

\section{CURRENT STATUS OF COVID-19 PANDEMIC IN THE UAE}

The United Arab Emirates, as of 27 December 2020, has a COVID- 19 cases recovery rate of almost 89\% and has recorded 669 COVID-19 deaths since the epidemic began [13]. The case fatality percentage is $0.3 \%$ and is lower compared to other developed countries. As of 29 December 2020, 209734.9 tests per 100K population are done with the positive rate of 1.2\% [14] (Figure 1). The UAE leads in global COVID-19 testing, the number of tests conducted per 1000 people is highest in the UAE compared to other developed nations.

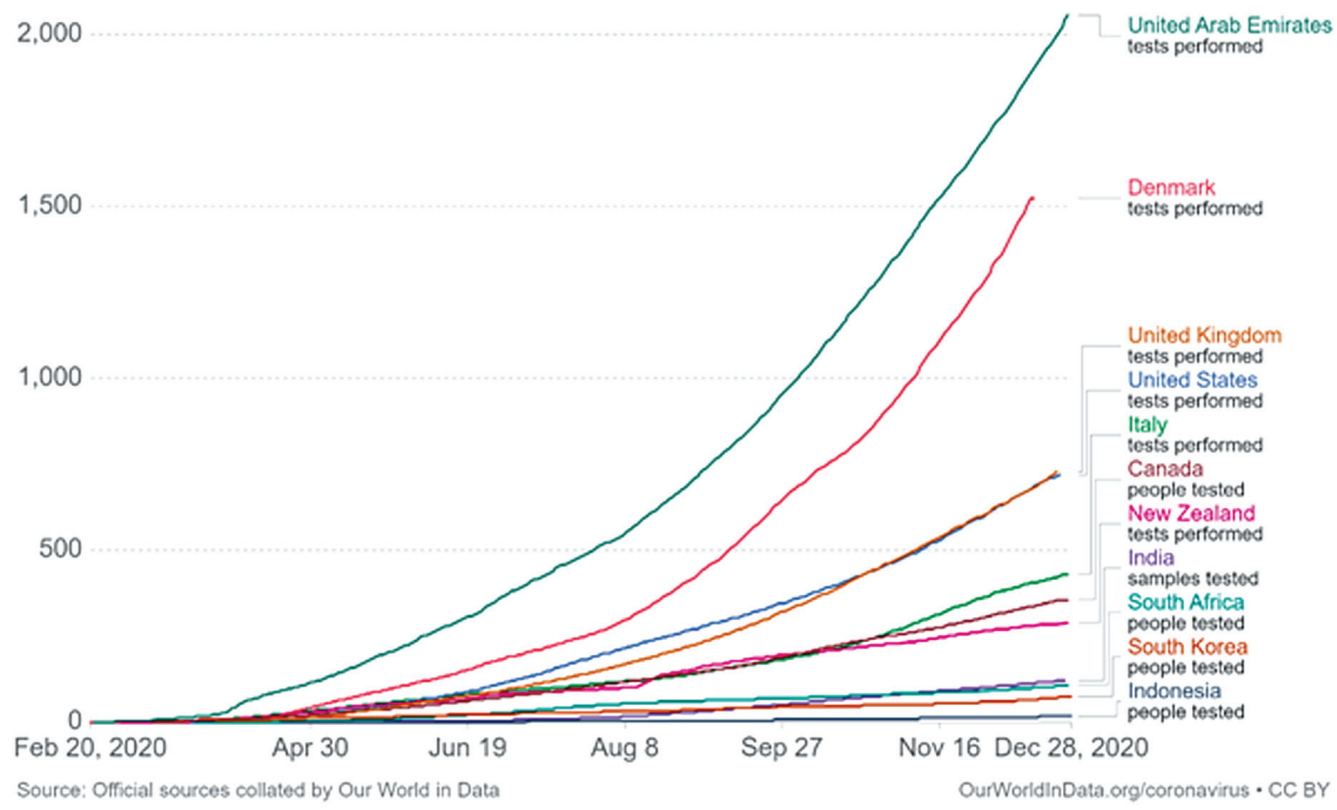

Figure 1. The graph shows the number of tests conducted per 1000 people.

\section{WAY FORWARD}

The UAE moves forward with successfully reopening the economy and addressing the newer challenges of the pandemic like the newer variants of the virus.

The UAE government encourages research and development of newer technologies with regards to COVID-19 pandemic and aligned to the nation's objectives, G42 Healthcare introduced the LamPORE technology with strategic global partnerships that is now integral to the UAE national testing program [15].

G42 Healthcare has implemented a COVID-19 virus genomic sequencing study aimed at monitoring the pattern of spread and evolution of the virus since the start of the pandemic. This sequencing will also identify the emergence of new strains. Studies have already been published from the UAE on genomic sequencing of COVID-19 virus which has contributed to the understanding of the global transmission network of SARS-CoV-2 [16].

Thus, the UAE has been efficient and effective in handling the crisis of COVID-19. It continues to pioneer in health care and serves as a leading example in the Middle East in comprehensively protecting the population and responsibly reopening the economy. 
Acknowledgements: We thank the reviewers for their constructive comments and suggestions.

Funding: None.

Authorship contributions: All authors contributed to writing and conceptualizing the manuscript.

Competing interests: The authors completed the ICMJE Unified Competing Interest form (available upon request from the corresponding author) and declare no conflicts of interest.

1 World Health Organization. Critical preparedness, readiness and response actions for COVID-19: interim guidance, 22 March 2020. Available: https://apps.who.int/iris/handle/10665/331511. Accessed: 15 November 2020

2 Novel coronavirus (2019 n-cov) alert 1. DOH. Media centre Publications. Available: https://doh.gov.ae/en/covid-19/MediaCenter/Publications. Accessed: 10 December 2020.

3 Department of Health. UAE. 2020. Available: https://www.doh.gov.ae/resources/Circulars. Accessed: 10 December 2020.

4 Khaleej Times. 21 March 2020. Available: https://www.khaleejtimes.com/coronavirus-outbreak/coronavirus-uae-ministry-clarifies-who-all-must-wear-masks-and-when. Accessed: 12 December 2020.

5 The United Arab Emirates. Government Portal. 2020. Available: https://u.ae/en/information-and-services/justice-safety-andthe-law/handling-the-covid-19-outbreak/smart-solutions-to-fight-covid-19. Accessed: 12 December 2020.

6 United Arab Emirates Ministry of Health and Prevention. Media center. 10 April 2020. Available: https://www.mohap.gov.ae/ en/MediaCenter/News/Pages/2365.aspx. Accessed: 12 December 2020.

7 The National. UAE Edition. 9 April 2020. Available: https://www.thenational.ae/uae/health/coronavirus-inside-a-covid-19-testing-tent-in-dubai-s-naif-area-1.1003577. Accessed: 29 December 2020.

8 Gulf news. 28 May 2020. Available: https://gulfnews.com/uae/health/coronavirus-uae-field-hospital-set-up-in-9-days-can-last10-years-1.71688370. Accessed: 29 December 2020.

9 The United Arab Emirates. Government Portal. 2020. Available: https://u.ae/en/information-and-services/justice-safety-andthe-law/handling-the-covid-19-outbreak/government-efforts-to-contain-covid-19. Accessed: 29 December 2020.

10 Ministry of Health and Prevention. UAE. Media Centre. Available: https://www.mohap.gov.ae/en/MediaCenter/News/Pages/2520.aspx. Accessed on 30 December 2020.

11 Khaleej Times. UAE Vaccine: Sinopharm's jab approved. 9th December 2020. Available: https://www.khaleejtimes.com/coronavirus-pandemic/uae-vaccine-for-coronavirus-sinopharms-jab-approved. Accessed: 30 December 2020.

12 Gulf News. 12 May 2020. Available: https://gulfnews.com/business/uae-to-build-post-covid-19-economy-on-digital-announces-two-phase-recovery-plan-1.1589306921373. Accessed: 2 January 2021.

13 Federal Competitiveness and Statistics Centre. UAE Ministry of Cabinet Affairs. 2020. Available: https://fcsa.gov.ae/en-us/Pages/ Covid19/UAE-Covid-19-Updates.aspx. Accessed: 28 December 2020.

14 Department of Health. UAE. 2020. Available: https://www.doh.gov.ae/en/covid-19/Media-Center/news/News-Listing/News102. Accessed: 26 December 2020

15 Al Arabiya. 19 August 2020. Available: https://english.alarabiya.net/en/coronavirus/2020/08/19/UAE-s-G42-to-work-with-Israeli-NanoScent-to-develop-COVID-19-detector-from-scent. Accessed: 30 December 2020.

16 Tayoun AA, Loney T, Khansaheb H, Ramaswamy S, Harilal D, Deesi ZO, et al. Multiple early introductions of SARS-CoV-2 into a global travel hub in the Middle East. Sci Rep. 2020;10:17720. Medline:33082405 doi:10.1038/s41598-020-74666-w

\section{Correspondence to:}

Dr. Subhashini Ganesan MD (Public Health)

Researcher

G42 Healthcare

Masdar City, Abu Dhabi

UAE

subhashini.g@g42.ai 